\title{
Early detection of biochemically occult autonomous thyroid nodules
}

\author{
N Brusca', C Virili', M Cellini', S Capriello', L Gargano ${ }^{2}$, R Salvatori³ ${ }^{3}$ M Centanni ${ }^{1,2}$ \\ and M G Santaguida' \\ ${ }^{1}$ Department of Medico-Surgical Sciences and Biotechnologies, 'Sapienza' University of Rome, Latina, Italy, \\ ${ }^{2}$ Endocrinology Unit, AUSL Latina, Latina, Italy and ${ }^{3}$ Department of Nuclear Medicine, AUSL Latina, Latina, Italy
}

\author{
Correspondence \\ should be addressed \\ to M Centanni \\ Email \\ marco.centanni@uniroma1.it
}

\begin{abstract}
Objective: Autonomously functioning thyroid areas may be associated with subclinical or overt hyperthyroidism, but may exist even in the presence of normal TSH. This study was aimed at comparing the rate of autonomously functioning areas and their cardiac sequelae in patients with nodular goitre studied with the usual and a novel approach.

Design and methods: In total 490 adult outpatients with thyroid nodular goitre, living in a mild iodine-deficient area, were selected in our referral centre for thyroid diseases from 2009 to 2014 on the basis of a suspicion of thyroid functional autonomy. They were divided in three groups according to a non-conventional approach (excessive response to thyroxine treatment: group 1) or conventional approach (low/normal TSH with clinical suspicion or low TSH: groups 2 and 3). All patients of the study with the suspicion of thyroid functional autonomy underwent thyroid scan with radioactive iodine (I31) uptake (RAIU).

Results: The percentage of confirmed thyroid functional autonomy was 319/490, being significantly higher in group 3 than in groups 1 and 2 ( 81.5 vs 64.7 vs $52.6 \%$; chi-square $P<0.0001$ ). However, the diagnosis with non-conventional approach was made at a significant earlier age $(P<0.0001)$. Cardiac arrhythmias as well as atrial fibrillation were similarly detected by conventional and non-conventional approaches (chi-square test: $P=0.2537 ; P=0.8425$ ). Conclusions: The hyper-responsiveness to thyroxine treatment should induce the suspicion of thyroid functional autonomy at an early stage, allowing to detect autonomous functioning areas in apparently euthyroid patients.
\end{abstract}

\section{Introduction}

The natural history of nontoxic goitre, in areas of iodine deficiency, encompasses a progressive increase in size (diffuse goitre) and/or development of multiple nodules (nodular goitre, NG) $(1,2,3)$. Despite its long-lasting euthyroid phase, thyroid functional autonomy may occur in both diffuse and NG, with greater frequency in the latter $(6.4 \%$ vs $21.2 \%)$ (4). The progression towards thyroid autonomy depends on genetic predisposition, somatic mutations of TSH receptor, iodine intake and older age $(1,2)$.

Autonomously functioning thyroid nodule (AFTN) may not only be associated with subclinical or overt hyperthyroidism $(2,5)$, but also with a normal TSH level
(C) 2016 European Society of Endocrinology Printed in Great Britain
(6). Increased cardiovascular morbidity and mortality have been reported in patients with overt hyperthyroidism, as well as in those with subclinical hyperthyroidism (7). In addition, atrial arrhythmias (sinus tachycardia, atrial premature beats and atrial fibrillation) are frequent sequelae of overt hyperthyroidism (5). Similar effects on cardiac function have been described even in subclinical hyperthyroid patients $(8,9,10)$, mostly in the elderly (11). Indeed, atrial fibrillation (12) is diagnosed in $2 \%$ of euthyroid people, $14 \%$ of overt hyperthyroid patients and $13 \%$ of patients with subclinical hyperthyroidism $(5,13)$.

Radioiodine thyroid scan (TS) represents so far the gold standard to detect autonomously functioning

Published by Bioscientifica Ltd. 
areas, and ATA guidelines suggest performing it in patients with low TSH (14). However, a recent metaanalysis underlines the importance of TS also in goitrous patients with TSH within the normal references to detect autonomous areas (6). In fact, low serum TSH is present only in half of patients with autonomous thyroid functional areas, as ascertained with TS (6). This raises the question whether occult autonomous areas may be not diagnosed in multinodular goitres showing normal serum TSH. So, there is a need for an early recognition of these occult autonomous areas in the thyroid even to prevent the cardiac sequelae (15).

Serum TSH is a recognized growth factor for thyroid nodules (16). In iodine-deficient areas (17), thyroxine treatment is used as yet to lower TSH to prevent growth of nodules and the appearance of new ones $(16,18)$. However, the efficacy and appropriateness of this treatment has been challenged, mainly in iodine sufficient areas $(2,3$, 19), also due to side effects related to the use of high doses of thyroxine (5). To date, increasing evidence showed the importance of using an individually tailored thyroxine dose to reach more safely target TSH $(20,21,22,23)$.

This study aims to evaluate the potential reliability of the use of tailored LT4 dose in detecting AFTN. This non-conventional approach was compared, in terms of potential clinical sequelae, to the conventional one adopting TS in patients with low TSH.

\section{Subjects and methods}

\section{Subjects}

A total of 2940 Caucasian outpatients with thyroid NG, living in a mild iodine-deficient area, were examined in our referral centre for thyroid diseases from 2009 to 2014. Of these, a total of 568 (19.3\%) patients with NG were selected based on the following suspicious features of thyroid functional autonomy: (1) patients treated with levothyroxine (L-T $\left.{ }_{4}\right)$ that showed TSH less than the expected level (TSH target: $0.1-0.4 \mathrm{mU} / \mathrm{L}$ ) or a TSH target with a L-T $\mathrm{T}_{4}$ dose lower than the one observed in a carefully checked reference group ('non-conventional' suspicion); (2) untreated patients with TSH value in the lower part of the normal range $(0.4-2.0 \mathrm{mU} / \mathrm{L})$ in the presence of cardiovascular (i.e. increased heart rate, arrhythmia) and extra-cardiovascular symptoms (anxiety, irritability, etc.) ('fairly conventional' suspicion); (3) untreated patients with subnormal TSH value $(<0.4 \mathrm{mU} / \mathrm{L})$ and in the presence of clinical symptoms of hyperthyroidism ('conventional' suspicion).
Exclusion criteria were (a) overt hyperthyroidism; (b) autoimmune, factitious, post-inflammatory or iatrogenic hyperthyroidism; (c) recent use of iodine products and drugs able to affect thyroid function $(24,25)$; (d) lack of patient's compliance; and (e) pregnancy and breastfeeding.

Based on these criteria, 78 patients were excluded and the remaining 490 patients represented the study group (384 female and 106 male, median age: 59 years): 156 patients belonging to group $1(136 \mathrm{~F} / 20 \mathrm{M}$; median age: 52 years), 188 belonging to group 2 (145F/43M; median age: 62 years) and 146 to group $3(103 \mathrm{~F} / 43 \mathrm{M}$; median age: 66 years) (Table 1). The diagnosis of NG was based on clinical and ultrasonographic features, as described previously (26). In adult patients belonging to group 1 , thyroxine treatment has been used to lower TSH, as still accepted in iodine-deficient areas in patients with evidence of non-neoplastic nodular growth $(16,17,18)$. Elderly patients were in long-lasting treatment, either started previously in our institution or, more often, prescribed in other hospitals. In all patients, any side effect possibly related to thyroxine treatment has led to an immediate drug withdrawal.

The internal reference group, needed as a benchmark for thyroxine treatment, consisted of 124 patients (110F/14M; median age: 54 years; 88 patients with less than 60 years and 36 patients with more than 60 years) with nontoxic NG (NTNG) in semi-suppressive

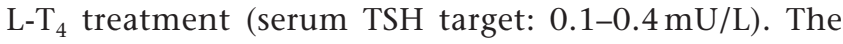
individually daily thyroxine dose was titrated on the basis of patients' body weight (kg) and age, as described previously $(21,26,27)$. In this group, the presence of thyroid functional autonomy, gastrointestinal disorders and other major interferences (see Liwanpo for rev (25)) as well as cardiac disorders has been positively excluded. Patients belonging to the reference group and those with 'non-conventional' suspicion were educated to take thyroxine fasting since at least $3 \mathrm{~h}$ and to wait at least $1 \mathrm{~h}$ before ingest any food or drink, except water. Moreover, we informed patients to wait at least $3 \mathrm{~h}$ before to take other drugs, in order to avoid interferences with the absorption kinetic of thyroxine, according to more recent literature $(28,29,30,31)$.

Table 1 Patients' characteristics.

\begin{tabular}{|c|c|c|c|}
\hline & Group 1 & Group 2 & Group 3 \\
\hline Patients $(n)$ & 156 & 188 & 146 \\
\hline Sex (female/male) & $136 \mathrm{~F} / 20 \mathrm{M}$ & $145 \mathrm{~F} / 43 \mathrm{M}$ & $103 F / 43 M$ \\
\hline Median age (years) & 52 & 62 & 66 \\
\hline Median TSH (mU/L) & 1.21 & 0.80 & 0.12 \\
\hline
\end{tabular}


A single levothyroxine brand was used in all treated patients (Eutirox - Bracco, Milan, Italy; since July 2013 Merck Serono S.p.A.), to prevent possible differences in bioequivalence (32).

\section{Design of the study}

The 156 patients with NG in semi-suppressive thyroxine therapy ('non-conventional' suspicion, group 1) were subdivided into two age-related groups (adult $<60$ years and elderly $>60$ years) and each group has been compared with the corresponding age-related reference group (Table 2). This was done to avoid bias due to the lower $\mathrm{T}_{4}$ requirement in elderly $(1,5)$. So far, in the adult reference group the desired serum TSH (median $=0.20 \mathrm{mU} / \mathrm{L}$ ) was reached at a median $\mathrm{L}-\mathrm{T}_{4}$ dose of $1.56 \mu \mathrm{g} / \mathrm{kg} / \mathrm{day}$. In the study group, despite the lower $\mathrm{L}_{-} \mathrm{T}_{4}$ dose $(P<0.0001)$, the adult patients exhibited a lower TSH level $(P<0.0001)$ (Table 2). Similar results were observed in the elderly patients: a median ${\mathrm{L}-\mathrm{T}_{4}}_{4}$ dose of $1.33 \mu \mathrm{g} / \mathrm{kg} / \mathrm{day}$ and a median serum TSH of $0.22 \mathrm{mU} / \mathrm{L}$ were observed in the reference group, while, in the study group, a significantly lower $\mathrm{L}_{-} \mathrm{T}_{4}$ dose $(P<0.0001)$ led to a median serum $\mathrm{TSH}$ of $0.07 \mathrm{mU} / \mathrm{L}(P=0.0727)$ (Table 2$)$. Hence, these patients were considered hyper-responsive to thyroid treatment regardless of age. Data were, thus, merged together and compared with those of goitrous patients with conventional suspicion of thyroid autonomy.

All patients of the study with the suspicion of thyroid functional autonomy underwent TS with radioactive iodine $\left(\mathrm{I}^{131}\right)$ uptake (RAIU). Obviously, in the patients with 'non-conventional' suspicion, the ${\mathrm{L}-\mathrm{T}_{4}}_{4}$ treatment was previously discontinued. When the results of TS were inconclusive, the patients underwent to a second TS and radioiodine uptake after triiodothyronine $\left(\mathrm{T}_{3}\right)$ administration (20-25 $\mu \mathrm{g}$ for three times in the day, for 8-10 days) (Werner's test) (33).

Study has been conducted upon written informed consent and as part of the diagnostic and therapeutic

Table 2 Age-related characteristics of thyroxine treated patients.

\begin{tabular}{|c|c|c|c|}
\hline & Group 1 & $\begin{array}{c}\text { Reference } \\
\text { group }\end{array}$ & $\boldsymbol{P}$ \\
\hline$<60$ years $(n)$ & 114 & 88 & \\
\hline Median TSH with $\mathrm{T}_{4}(\mathrm{mU} / \mathrm{L})$ & 0.08 & 0.20 & $<0.0001$ \\
\hline $\mathrm{T}_{4}$ dose/weight ( $\mu \mathrm{g} / \mathrm{kg} /$ day) & 1.20 & 1.56 & $<0.0001$ \\
\hline$>60$ years $(n)$ & 42 & 36 & \\
\hline Median TSH with $\mathrm{T}_{4}(\mathrm{mU} / \mathrm{L})$ & 0.07 & 0.22 & 0.0727 \\
\hline $\mathrm{T}_{4}$ dose/weight ( $\mu \mathrm{g} / \mathrm{kg} /$ day) & 0.93 & 1.33 & $<0.0001$ \\
\hline
\end{tabular}

workup of the patients involved, according to the local ethical rules and to the guidelines in the Declaration of Helsinki.

\section{Methods}

Serum TSH levels were measured by commercial kit (Thermo Scientific, BRAHMS TSH RIA) (normal range: 0.4$4.0 \mathrm{mU} / \mathrm{L}$; sensitivity: $0.04 \mathrm{mU} / \mathrm{L}$; intra-assay and interassay variation were $2.5 \%$ and $4.1 \%$, respectively). Levels of serum free $\mathrm{T}_{4}$ were detected by commercial kit (Thermo Scientific, BRAHMS FT 4 RIA) (normal range: 10-25 pmol/L, which is the equivalent of $0.78-1.94 \mathrm{ng} / \mathrm{dL}$ ), as the levels of serum free $\mathrm{T}_{3}$ (normal range: $3.5-8.1 \mathrm{pmol} / \mathrm{L}$ or 2.3$5.3 \mathrm{pg} / \mathrm{mL})$. Serum anti-thyroid peroxidase antibodies (TPO-Ab) levels were detected by commercial kit (Thermo Scientific, BRAHMS anti-TPO) (normal range: $<60 \mathrm{U} / \mathrm{mL}$ ). The anti-TSHreceptor antibodies (TRAb) levels were measured by commercial kit (Thermo Scientific, BRAHMS TRAK Human RIA).

\section{Statistical analysis}

Data are expressed as median value (Interquartile range: IQ1 and IQ3) and were analysed by nonparametric Mann-Whitney $U$ test. The differences among the groups were calculated using the Fisher's exact test or chi-square test. INSTAT GraphPad Prism 5.0 software for Windows was used in the statistical analysis.

\section{Results}

The 156 treated patients with NG, despite a low dose of thyroxine (median $\mathrm{T}_{4}=1.17 \mu \mathrm{g} / \mathrm{kg} /$ day), had a median TSH of $0.079 \mathrm{mU} / \mathrm{L}$ (IQ1-IQ3=0.02-0.30 mU/L) ('nonconventional' suspicion, group 1). After withdrawal of thyroxine treatment, TSH level was restored into normal range (median $\mathrm{TSH}=1.21 \mathrm{mU} / \mathrm{L}$ ). All these patients underwent scants, which confirmed the diagnosis of thyroid functional autonomy in $101 / 156$ patients $(64.7 \%)$, while in the remaining 55 patients (35.3\%) the suspicion was not confirmed (Fig. 1). Interestingly, the median TSH, without thyroxine treatment, was not different in the patients with or without confirmed areas of autonomy (median TSH: 1.28 vs $1.12 \mathrm{mU} / \mathrm{L} ; P=\mathrm{ns}$ ). In contrast, both the early iodine uptake at 4 th hour (16.27 vs $13 \%$; $P=0.0378)$ and the total iodine uptake at 24 th hour (31.91 vs $25.28 \% ; P=0.0006)$ were significantly different in confirmed and non-confirmed patients (Fig. 2A). 


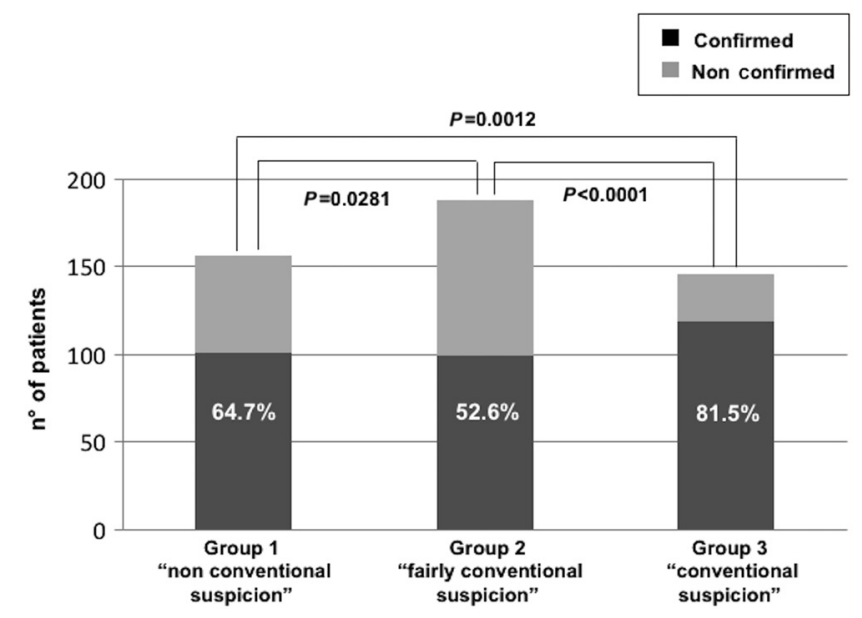

Figure 1

Distribution of percentages of patients with confirmed areas of autonomy in the study groups. Data were analysed by nonparametric Mann-Whitney $U$ test.

These data were compared with those obtained in the other groups of patients investigated on the basis of 'fairly conventional' and 'conventional' suspicion. The 188 patients with NG and 'fairly conventional' suspicion of thyroid functional autonomy (group 2) showed a median TSH=0.80 mU/L (IQ1-IQ3: $0.60-0.95 \mathrm{mU} / \mathrm{L}$ ). In $99 / 188$ patients $(52.6 \%)$ the suspicion of an autonomously functioning area was confirmed and excluded in the remaining 89. Unlike group 1 , the median iodine uptake at 4 th hour and 24th hour was similar, 12.34 vs $12.83 \%$ and $26 \%$ vs $26 \%$, respectively, in the confirmed and in non-confirmed patients ( $P=$ ns) (Fig. 2B). In the 146 patients with NG and 'conventional' suspicion of thyroid functional autonomy (group 3) a median TSH level of 0.12 mU/L (IQ1-IQ3: 0.03-0.26 mU/L) was observed. In $119 / 146$ patients $(81.5 \%)$ the presence of an autonomously functioning area was confirmed by the TS, while in 27 was excluded. The median radioiodine uptake at 4 th hour was significantly higher $(P=0.013)$ in those with proven areas of autonomy than in those non-confirmed (median uptake: $14 \%$ vs $11.9 \%$ ). A similar trend was observed even at 24 th hour (28.16\% vs $25.09 \%$; $P=0.0094)$ (Fig. 2C).

So far, the percentage of patients with confirmed thyroid autonomy was higher in group 3 (low serum TSH) than in patients with normal TSH (groups 1 and 2) (chi-square $P<0.0001$ ) (Fig. 1), whereas the percentage of thyroid autonomy in group 1 ('non-conventional' approach) (64.7\%) is equal to the one in group 2 and 3 pooled together ('fairly' and 'conventional' approach) (65\%) (Fisher's exact test: $P=0.9192)$.

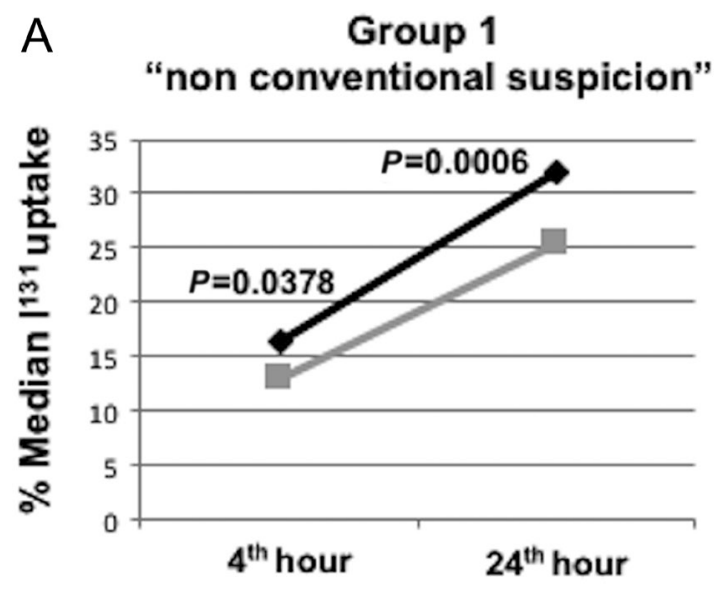

B

Group 2 "fairly conventional suspicion"
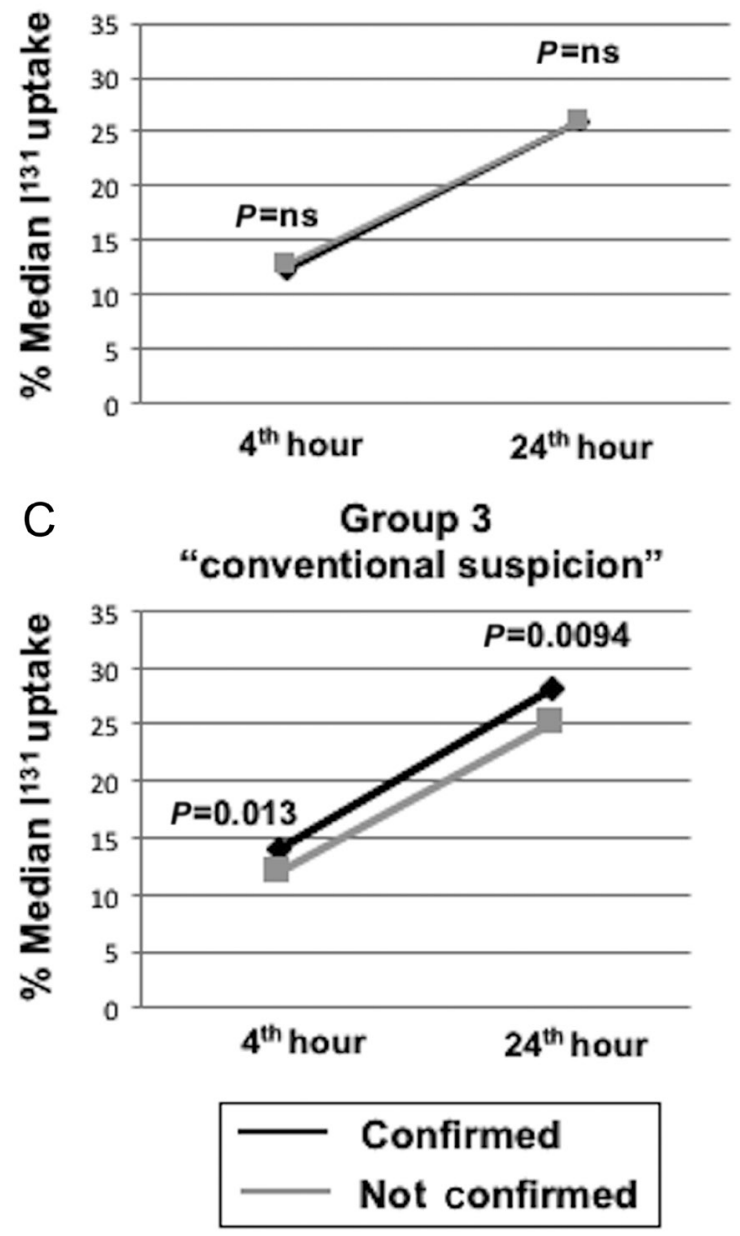

Figure 2

The median iodine uptake at 4th and 24th hour in patients with confirmed areas of autonomy and in those without diagnostic confirmation in the study groups. Data were analysed by nonparametric Mann-Whitney $U$ test. 
Table 3 Cardiac arrhythmias in the study groups.

All patients with cardiac arrhythmias (CA)

Patients with CA and confirmed areas of autonomy

Patients with atrial fibrillation and confirmed areas of autonomy

\begin{tabular}{|c|c|}
\hline $\boldsymbol{n}(\mathrm{F} / \mathrm{M})$ & Median age, years \\
\hline $85(69 / 16)$ & 64 \\
\hline $62(50 / 12)$ & 65 \\
\hline $25(20 / 5)$ & 69 \\
\hline
\end{tabular}

\begin{tabular}{c}
\hline Group 2 \\
\hline $39 / 188$ \\
$25 / 99$ \\
$9 / 99$ \\
\hline
\end{tabular}

\begin{tabular}{c}
$\boldsymbol{P}$ \\
\hline 0.2537 \\
0.2003 \\
0.8425
\end{tabular}

Owing to the fact that autonomously functioning areas is highly associated with cardiac arrhythmias (tachycardia, extrasystoles, atrial fibrillation) (9), the presence of these disorders were investigated in the whole study group. A total of 85 (69F/16M; median age: 64 years) out of 490 patients with NG (17.3\%) showed heart rhythm disorders. Notably, a cardiac arrhythmia has been found in 22/156 patients (14.1\%) in group 1, in 39/188 patients $(20.7 \%)$ in group 2 and in 24/146 patients (16.4\%) in group 3, being these differences not statistically significant (chi-square test: $P=0.2537)$ (Table 3). Also no difference $(P=0.2755)$ was observed by merging data from 'non-conventional' and 'fairly conventional' suspicion, showing similar TSH values, and comparing them with data in patients with low serum TSH.

Among the 319 patients with proven areas of thyroid autonomy, 62 patients (50F/12M; median age: 65 years) had a cardiac arrhythmias (19.4\%), representing $72.9 \%$ of all patients (62/85) with heart rhythm disorders (Fig. 3). Analysis of the subgroups revealed that there were no

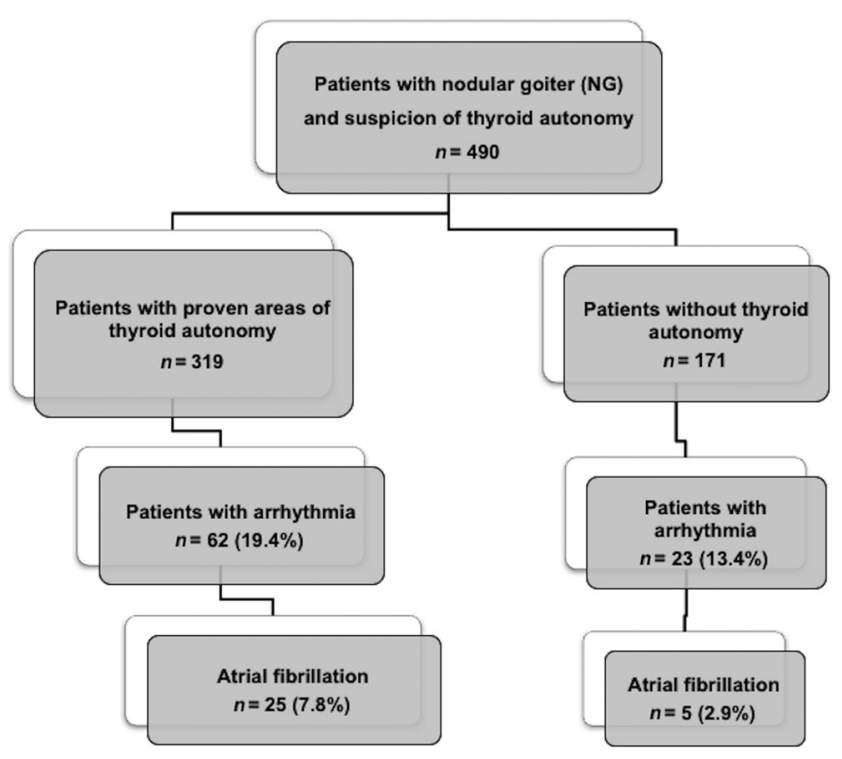

Figure 3

Overview of arrhythmias and atrial fibrillation in patients with or without proven areas of autonomy. differences in rate of cardiac arrhythmias among the groups (chi-square test: $P=0.2003$ ) (Table 3 ). Noticeably, the median age was significantly higher in patients with low serum TSH (group 3; median age: 70 years) than in patients with normal TSH, both untreated (group 2; median age: 64 years; $P=0.0103)$ and treated with $\mathrm{T}_{4}$ (group 1; median age: 55 years; $P=0.0019$ ) (Table 3 ).

Overall, among 85 patients with heart rhythm disorders, some 30 patients (35\%) had one or more events of atrial fibrillation (paroxysmal or chronic). In 5 of these, atrial fibrillation was not related with thyroid disorder and therefore it represented the $40 \%$ (25/62) of all arrhythmias diagnosed in patients with thyroid autonomy. Again, the rate of atrial fibrillation was similarly detected by conventional and non-conventional approaches (group 1: 7/101 (6.93\%); group 2: 9/99 (9.1\%); group 3: 9/119 (7.56\%); chi-square test: $P=0.8425$ ] (Table 3 ).

\section{Discussion}

The findings of this study have shown that (a) the low serum TSH level is a reliable but belated index associated with hyperfunctioning nodules; (b) normal serum TSH may be also associated with autonomous thyroid areas; (c) by the described 'non-conventional' approach, we have identified a substantial percentage of occult autonomous areas as well; (d) heart arrhythmias were not related to serum TSH but rather to the presence of autonomous areas, even occult.

In iodine-deficient areas, the natural history of nontoxic goitre encompasses its functional transition to thyroid autonomy $(2,34)$, which increases with age and may be recognizable in some $15 \%$ of elderly patients (35). This study agreed with the other reports stating that low serum TSH is a good predictor for the existence of thyroid areas with functional autonomy (14). Nevertheless, this study demonstrated that the TS, performed in carefully selected patients with normal TSH, detects early a significant number of patients with autonomous thyroid function areas and cardiac arrhythmias. This is not fully in keeping with Recommendation 2 (moderate quality evidence) in 
the ATA thyroid nodules guidelines which support the notion that scintiscan should be performed only when serum TSH is low (14). However, the recognition of these hyperfunctioning areas through that approach may not be early enough; recent studies, in fact, demonstrated that thyroid functional autonomy may exist even in patients with normal serum TSH levels and our results showed that this occurs several years before the appearance of low serum TSH. Coexistence of normal serum TSH levels and AFTN may occur in patients with apparently euthyroid goitre and in those with goitre associated with Hashimoto's thyroiditis $(6,15,36,37)$. Indeed, in euthyroid goitres, small/subcentimetric areas of 'hot' thyroid tissue partially inhibit the remaining follicles, but the little amount of autonomous tissue and/or the low synthesis rate of iodothyronines prevent TSH suppression $(6,15)$. Similarly, in patients with untreated Hashimoto's thyroiditis, the hypothyroidism, due to the progressive autoimmune destruction of thyroid tissue, is counteracted by the presence of one or more autonomous areas (36). The final balance among these opposite functional activities may sometime lead to normal TSH level (36). These areas of thyroid autonomy may remain occult for years (34), but the risk of developing hyperthyroidism may occur in both cases $(6,36)$ and so novel and easy diagnostic tools are needed to identify them at earlier stages.

On this ground, our data suggest that hyperresponsiveness to thyroxine treatment may be useful to suspect the presence of an occult autonomous thyroid areas at an early stage. We used a similar approach when we studied patients with $\mathrm{T}_{4}$ malabsorption $(22,23,38$, 39 ): in that case, TSH levels higher than expected led us to look for occult gastrointestinal disorders while in this study, a TSH lower than expected helped us to detect functional thyroid autonomy. This 'non-conventional' approach is as efficient as the conventional methods; in fact, the diagnosis of thyroid functional autonomy has been confirmed in about two-third of patients who hyper-responded to thyroxine treatment, a fraction similar to the one recorded with the conventional approach. Noticeably, after $\mathrm{T}_{4}$ treatment withdrawal, these patients had a normal TSH level, showing that this approach identified thyroid autonomy when still in an occult phase.

Arrhythmias are a major concern in patients with subclinical or overt hyperthyroidism, since their prevalence is greatly increased in these patients as compared with general population $(7,13)$. The linkage between autonomous functioning areas and cardiac arrhythmias, independently from thyroid function, is as yet scarcely described. Our study shows that one-fifth of patients with thyroid autonomously functioning areas have cardiac arrhythmias and some one-tenth has atrial fibrillation. It should be emphasized that the number of arrhythmias and that of atrial fibrillation were similar in patients with low and normal serum $\mathrm{TSH}$, despite patients with low TSH were older, in agreement with the literature (40). Based on these data, thyroid functional autonomy may represent in itself a risk factor for atrial fibrillation, even when serum TSH is normal. Interestingly, there was no whatsoever difference in the frequency of arrhythmias and atrial fibrillation depending on the approach used. To note, the non-conventional approach (hyper-responsiveness to thyroxine treatment) to thyroid autonomy has been proven equivalent to conventional approach (low TSH or normal TSH with symptoms), even in detecting cardiac arrhythmias.

In conclusion, this study shows that the hyperresponsiveness to thyroxine treatment should induce the suspicion of a thyroid functional autonomy at an early stage, allowing to detect autonomous functioning areas in apparently euthyroid patients. Cardiac arrhythmias, and chiefly atrial fibrillation, can be also associated to occult thyroid functional autonomy, though TSH would be normal. These data indicated that a low serum TSH may be not an early and exhaustive marker to diagnose thyroid functional autonomy and related arrhythmias.

Declaration of interest

$M C$ received honorarium for symposia from Akrimax Pharmaceuticals LLC USA. The other authors have no conflict of interest and nothing to disclose.

\section{Funding}

This research did not receive any specific grant from any funding agency in the public, commercial or not-for-profit sector.

\section{References}

1 Tonacchera M, Pinchera A \& Vitti P. Assessment of nodular goiter. Best Practice and Research Clinical Endocrinology and Metabolism 201024 51-61. (doi:10.1016/j.beem.2009.08.008)

2 Hegedus L, Bonnema SJ \& Bennedbaek FN. Management of simple nodular goiter: current status and future perspectives. Endocrine Reviews 200324 102-132. (doi:10.1210/er.2002-0016)

3 Bahn RS \& Castro MR. Approach to the patient with nontoxic multinodular goiter. Journal of Clinical Endocrinology and Metabolism 201196 1202-1212. (doi:10.1210/jc.2010-2583)

4 Papi G, Pearce EN, Braverman LE, Betterle C \& Roti E. A clinical and therapeutic approach to thyrotoxicosis with thyroid-stimulating 
hormone suppression only. American Journal of Medicine 2005118 349-361. (doi:10.1016/j.amjmed.2005.01.004)

5 Biondi B \& Cooper DS. The clinical significance of subclinical thyroid dysfunction. Endocrine Reviews 200829 76-131. (doi:10.1210/er.20060043)

6 Treglia G, Trimboli P, Verburg FA, Luster M \& Giovanella L. Prevalence of normal TSH value among patients with autonomously functioning thyroid nodule. European Journal of Clinical Investigation 201545 739-744. (doi:10.1111/eci.12456)

7 Biondi B \& Kahaly GJ. Cardiovascular involvement in patients with different causes of hyperthyroidism. Nature Reviews Endocrinology 2010 6 431-443. (doi:10.1038/nrendo.2010.105)

8 Intenzo C, Jabbour S, Miller JL, Ahmed I, Furlong K, Kushen M, Kim SM \& Capuzzi DM. Subclinical hyperthyroidism: current concepts and scintigraphic imaging. Clinical Nuclear Medicine 201136 e107-e113. (doi:10.1097/RLU.0b013e3182175477)

9 Kahaly GJ \& Dillmann WH. Thyroid hormone action in the heart. Endocrine Reviews 200526 704-728. (doi:10.1210/er.2003-0033)

10 Surks MI, Ortiz E, Daniels GH, Sawin CT, Col NF, Cobin RH, Franklyn JA, Hershman JM, Burman KD, Denke MA et al. Subclinical thyroid disease: scientific review and guidelines for diagnosis and management. JAMA $2004291228-238$. (doi:10.1001/jama.291.2.228)

11 Gammage MD, Parle JV, Holder RL, Roberts LM, Hobbs FD, Wilson S, Sheppard MC \& Franklyn JA. Association between serum free thyroxine concentration and atrial fibrillation. Archives of Internal Medicine 2007167 928-934. (doi:10.1001/archinte.167.9.928)

12 Heeringa J, Hoogendoorn EH, van der Deure WM, Hofman A, Peeters RP, Hop WC, den Heijer M, Visser TJ \& Witteman JC. High-normal thyroid function and risk of atrial fibrillation. The Rotterdam Study. Archives of Internal Medicine 2008168 2219-2224. (doi:10.1001/archinte.168.20.2219)

13 Cooper DS. Approach to the patient with subclinical hyperthyroidism. Journal of Clinical Endocrinology and Metabolism 2007 92 3-9. (doi:10.1210/jc.2006-2472)

14 Haugen BR, Alexander EK, Bible KC, Doherty G, Mandel SJ, Nikiforov YE, Pacini F, Randolph G, Sawka A, Schlumberger M et al. 2015 American thyroid association management guidelines for adult patients with thyroid nodules and differentiated thyroid cancer. Thyroid 201626 1-133. (doi:10.1089/thy.2015.0020)

15 Ianni F, Perotti G, Prete A, Paragliola RM, Ricciato MP, Carrozza C, Salvatori M, Pontecorvi A \& Corsello SM. Thyroid scintigraphy: an old tool is still the gold standard for an effective diagnosis of autonomously functioning thyroid nodules. Journal of Endocrinological Investigation 201336 233-236. (doi:10.3275/8471)

16 Fiore E \& Vitti P. Serum TSH and risk of papillary thyroid cancer in nodular thyroid disease. Journal of Clinical Endocrinology and Metabolism 201297 1134-1145. (doi:10.1210/jc.2011-2735)

17 Vitti P, Delange F, Pinchera A, Zimmermann M \& Dunn JT. Europe is iodine deficient. Lancet $2003 \mathbf{3 6 1}$ 1226. (doi:10.1016/S01406736(03)12935-2)

18 Zelmanovitz F, Genro S \& Gross JL. Suppressive therapy with levothyroxine for solitary thyroid nodules: a double-blind controlled clinical study and cumulative meta-analyses. Journal of Clinical Endocrinology and Metabolism 199883 3881-3885. (doi:10.1210/ jc.83.11.3881)

19 Filetti S, Durante C \& Torlontano M. Nonsurgical approaches to the management of thyroid nodules. Nature Clinical Practice Endocrinology and Metabolism 20062 384-394. (doi:10.1038/ncpendmet0215)

20 Mercuro G, Panzuto MG, Bina A, Leo M, Cabula R, Petrini L, Pigliaru F \& Mariotti S. Cardiac function, physical exercise capacity, and quality of life during long term thyrotropin-suppressive therapy with levothyroxine: effect of individual dose tailoring. Journal of Clinical Endocrinology and Metabolism 200085 159-164. (doi:10.1210/ jcem.85.1.6298)
21 Del Duca SC, Santaguida MG, Brusca N, Gatto I, Cellini M, Gargano L, Verga Falzacappa C, Frattaroli FM, Virili C \& Centanni M. Individually-tailored thyroxine requirement in the same patients before and after thyroidectomy: a longitudinal study. European Journal of Endocrinology 2015173 351-357. (doi:10.1530/EJE-15-0314)

22 Centanni M. Thyroxine treatment: absorption, malabsorption, and novel therapeutic approaches. Endocrine 201343 8-9. (doi:10.1007/ s12020-012-9814-9)

23 Cellini M, Santaguida MG, Gatto I, Virili C, Del Duca SC, Brusca N, Capriello S, Gargano L \& Centanni M. Systematic appraisal of lactose intolerance as cause of increased need for oral thyroxine. Journal of Clinical Endocrinology and Metabolism 201499 E1454-E1458. (doi:10.1210/jc.2014-1217)

24 Surks MI \& Sievert R. Drugs and thyroid function. New England Journal of Medicine 1995333 1688-1694. (doi:10.1056/ NEJM199512213332507)

25 Liwanpo L \& Hershman JM. Conditions and drugs interfering with thyroxine absorption. Best Practice and Research Clinical Endocrinology and Metabolism 200923 781-792. (doi:10.1016/ j.beem.2009.06.006)

26 Centanni M, Gargano L, Canettieri G, Viceconti N, Franchi A, Delle Fave G \& Annibale B. Thyroxine in goiter, Helicobacter pylori infection, and chronic gastritis. New England Journal of Medicine 2006 354 1787-1795. (doi:10.1056/NEJMoa043903)

27 Santaguida MG, Virili C, Del Duca SC, Cellini M, Gatto I, Brusca N, De Vito C, Gargano L \& Centanni M. Thyroxine softgel capsule in patients with gastric-related T4 malabsorption. Endocrine 201549 51-57. (doi:10.1007/s12020-014-0476-7)

28 Benvenga S, Bartolone L, Squadrito S, Lo Giudice F \& Trimarchi F. Delayed intestinal absorption of levothyroxine. Thyroid $1995 \mathbf{5}$ 249-253. (doi:10.1089/thy.1995.5.249)

29 Virili C, Trimboli P, Romanelli F \& Centanni M. Liquid and softgel levothyroxine use in clinical practice: state of the art. Endocrine 2016 In press. (doi:10.1007/s12020-016-1035-1)

30 Benvenga S, Bartolone L, Pappalardo MA, Russo A, Lapa D, Giorgianni G, Saraceno G \& Trimarchi F. Altered intestinal absorption of L-thyroxine caused by coffee. Thyroid 200818 293-301. (doi:10.1089/thy.2007.0222)

31 Bach-Huynh TG, Nayak B, Loh J, Soldin S \& Jonklaas J. Timing of levothyroxine administration affects serum thyrotropin concentration. Journal of Clinical Endocrinology and Metabolism 2009 94 3905-3912. (doi:10.1210/jc.2009-0860)

32 Green WL. New questions regarding bioequivalence of levothyroxine preparation: a clinician's response. AAPS Journal 20057 E54-E58. (doi:10.1208/aapsj070107)

33 Napolitano G \& Monaco F. Pretoxic and toxic autonomous nodule. In Thyroid Disease, pp 347. Ed F Monaco. CRC Press by Taylor \& Francis Group, 2012.

34 Knobel M. Etiopathology clinical features, and treatment of diffuse and multinodular nontoxic goiters. Journal of Endocrinological Investigation 201639 357-373. (doi:10.1007/s40618-015-0391-7)

35 Aghini-Lombardi F, Antonangeli L, Martino E, Vitti P, Maccherini D, Leoli F, Rago T, Grasso L, Valeriano R, Balestrieri A et al. The spectrum of thyroid disorders in an iodine-deficient community: the Pescopagano survey. Journal of Clinical Endocrinology and Metabolism 199984 561-566. (doi:10.1210/jc.84.2.561)

36 Ruggeri RM, Campennì A, Sindoni A, Baldari S, Trimarchi F \& Benvenga S. Association of autonomously functioning thyroid nodules with Hashimoto's thyroiditis: study on a large series of patients. Experimental and Clinical Endocrinology and Diabetes 2011 119 621-627. (doi:10.1055/s-0031-1279705)

37 Chami R, Moreno-Reyes R \& Corvilain B. TSH measurement is not an appropriate screening test for autonomous functioning thyroid nodules: a retrospective study of 368 patients. European Journal of Endocrinology 2014170 593-599. (doi:10.1530/EJE-13-1003) 
38 Centanni M, Gargano L, Canettieri G, Viceconti N, Franchi A, Delle Fave G \& Annibale B. Thyroxine in goiter, Helicobacter pylori infection, and chronic gastritis. New England Journal of Medicine 2006 354 1787-1795. (doi:10.1056/NEJMoa043903)

39 Virili C, Bassotti G, Santaguida MG, Iuorio R, Del Duca SC, Mercuri V, Picarelli A, Gargiulo P, Gargano L \& Centanni M. Atypical celiac disease as cause of increased need for thyroxine: a systematic study.
Journal of Clinical Endocrinology and Metabolism 201297 E419-E422. (doi:10.1210/jc.2011-1851)

40 Vadiveloo T, Donnan PT, Cochrane L \& Leese GP.The Thyroid Epidemiology, Audit, and Research Study (TEARS): morbidity in patients with endogenous subclinical hyperthyroidism. Journal of Clinical Endocrinology and Metabolism 201196 1344-1351. (doi:10.1210/jc.2010-2693)

Received 1 July 2016

Revised version received 9 September 2016

Accepted 19 September 2016 